Zhenhua Page 1

\title{
HICL table can manipulate all proteins in human complete proteome
}

Zhenhua Xie ${ }^{1,2^{*}}$

1 The Shenzhen Key Laboratory of Health Sciences and Technology, Graduate School at

Shenzhen, Tsinghua University, Shenzhen 518055, China

${ }^{2}$ Green biosynthesis institute of Bontac bio-engineering(shenzhen)Co.,Ltd, Shenzhen 518102, China

* Correspondence: xiezh@ sz.tsinghua.edu.cn

[Insert Running title of $<72$ characters] 


\section{Abstract}

\section{Background}

The data of human complete proteome in the databases of Universal Protein Resource (UniProt) or National Center for Biotechnology Information(NCBI) were disorderly organized and hardly handled by an ordinary biologist.

\section{Results}

The HICL table enable an ordinary biologist efficiently to handle the human complete proteome with 67911 entries, to get an overview on the distribution of the physicochemical features of all proteins in the human complete proteome, to perceive the details of the distribution patterns of the physicochemical features in some protein family members and protein variants, to find some particular proteins.

Moreover, two discoveries were made via the HICL table: (1) The amino aicds(Asp,Glu) have symmetrical trend of the distributions versus pI, but the amino aicds(Arg, Lys) have local asymmetrical trend of the distributions versus pI in human complete proteome. (2) Protein sequence, besides amino acid properties, can in theory influence the modal distribution of protein isoelectric points.

\section{Conclusion}

I has created the HICL table as a robust tool for orderly managing 67911 proteins in human complete proteome by their physicochemical features, the names and sequences. Any proteins with the particular physicochemical features can be screened out from the human complete proteome via the HICL table. In addition, the unbalanced distribution of the amino aicds(Arg, Lys) in high $\mathrm{pI}$ proteins of human complete proteome and the effect of protein sequence on modal distribution of protein isoelectric points have been discovered through the HICL table.

Keywords: complete proteome, amino acid composition, isoelectric point(pI), small protein, acidic protein, basic protein, lysine-rich protein, threonine-rich protein, tryptophan-rich protein, methionine-rich protein

\section{Background}

A complete proteome is a group of proteins expressed by a genome completely sequenced. Sequences of the proteins in a complete proteome can be translated from all protein coding genes of a genome completely sequenced[1,2,3]. The availability of several thousand complete proteomes for the fully sequenced organisms has enabled us to decipher the evolutionary history of species through global comparative analyses[4,5]. However, it has been a challenging task for an ordinary biologist to handle a complete proteome with the massive amounts of entries. A coordinate system of a complete proteome should be developed for handling a complete proteome efficiently. 
Mass spectrometry (MS)-based shotgun method is extremely powerful to analysize proteomes. Such a strategy relies heavily on the databases of complete proteomes[6,7]. In addition, 2D-PAGE approach has some its limitations: it can hardly separate very acidic, basic, small, large and hydrophobic proteins[8]. Therefore, organizing complete proteomes by physicochemical features of the protein sequences has become a strong need for the development of proteomics.

In order to interprete the biological functions of the many proteins in complete proteomes, sequence-sequence similarity or sequence-structure similarity play a critical role in predicting a possible function for a new sequence $[9,10]$. But these methods do not function properly when clear sequence or structural similarities do not exist as in case of far divergent evolution where sequence identities are below $25 \%[11]$. Morover, not all homologous proteins have analogous functions. Some proteins have many shared domains, but they have different functions[12]. After all, because only ninety percent of proteins in the human complete proteome can matched at least one of 5494 manually curated Pfam-A families[13], the classification system based on sequence- sequence similarity of proteins is not a complete and user-friendly classification system. Therefore, the sequence- independent physicochemical features of proteins could be chosen as parameters to handle a complete proteome.

Proteins can be broken down into their constituent amino acids (AAs). Hydrophobicity, isoelectric point(pI), sequence length and molecular weight of a protein are independent of the sequence order information and only dependent of the numbers of amino acid composition (AAC) of the protein, so these physicochemical features have been designated as AAC-derived physicochemical features. The values of these features can be extracted simplely from a linear amino acid sequence. AAC and AAC-derived physicochemical features are powerful features that can predict protein-protein interactions, structural and functional classes of proteins and subcellular locations[14-17].

Excel is widely used by biologists for data manipulation [18]. In this study, like geographical coordinate system that uses degrees of latitude, longitude and altitude to illustrate a location on the earth's surface, the values of AAC and AAC-derived physicochemical features had been chosen as multidimensional quantitative coordinates to locate all proteins in the human complete proteome. The values of intrinsic physicochemical features, ID numbers, names and Met-truncated sequences 
of all proteins in the human complete proteome had been organized as data matrix that was imported into Microsoft Excel(2007) to generate a excel table for manipulating of all protens in human complete proteome.

\section{Results and discussion}

\section{The organization of the data in the HICL excel table}

The HICL table was organized in 67912 rows and 28 columns and contains a header row and column for cell referencing. The numbers as showed in the header column represent the sequential numbers of the list of entries in the human complete proteome in FAST format, and the titles of columns in the header row use NO, Ala, Cys, Asp, Glu, Phe, Gly, His, Ile, Lys, Leu, Met, Asn, Pro, Gln, Arg, Ser, Thr, Val, Trp, Tyr, SL, MW, pI, HP, Annot1, Annot2, MTS to indicate the sequential number, the values of AAC, sequence length, molecular weight, pI, hydrophobicity, annotation and the corresponding Met-truncated sequence(MTS) of a protein. The all relative information of a protein was inserted in a corresponding row. The different parameters, annotations and MTSs of all proteins were respectively inserted in different corresponding columns for quickly manipulating the data of all protens in the human complete proteome. The annotation was devided to the protein name and ID number with the name abbreviation and -HUMAN for conveniently sorting all protens alphabetically according the names. All the names and ID numbers with the name abbreviations and -HUMAN were respectively inserted in the Annot1 and Annot2 columns.

Like geographical coordinate system that uses degrees of latitude, longitude and altitude to illustrate a location on the earth's surface, using the value of AAC, sequence length, molecular weight, $\mathrm{pI}$ and hydrophobicity as numerical coordinates, a proteome coordinate system has been developed in the excel table to describe the location of every protein of the human complete proteome. Based on the tool of the Remove Duplicates section of the Data tab, 71 rows were detected as redundant rows in total 67911 rows according to the values of either AAC and sequence length or all physicochemical features in the data of the HICL table. Therefore, The values of $\mathrm{AAC}$ and sequence length can provide fundamental 21-dimentional coordinate system to locate all proteins. The values of molecular weight, $\mathrm{pI}$ and hydrophobicity derived 
originally from the values of AAC and sequence length can not provide additional information for locating the proteins, but as derived coordinates, they have crucial role for sorting, grouping and searching of all protens in the human complete proteome.

The data of all proteins in the human complete proteome have been organized as the data matrix in the HICL table, and the data matrix can be reorganized by the values of physicochemical features, names or the Met-truncated sequences.

\section{Sorting all proteins of the human complete proteome by physicochemical}

\section{features}

The sorted HICL table can illustrate both overview and detail of the distribution of AAC, sequence length, molecular weight, $\mathrm{pI}$ and hydrophobicity of all proteins. The all values of the every column in the HICL table were divided into five groups according to corresponding grouping criteria. Detail of the grouping criteria was illustrated in the table 1 . The distributions of the all proteins in every numerical column of the HICL table were demonstrated in the table 2.

Lysine-rich proteins have nutritive and commercial value to establish transgenic lines of cereals with high lysine content of grains [20]. It was reported that down-regulation of cysteine-rich proteins and down-regulation of methionine-rich proteins can be respectively adopted by Escherichia coli and Synechocystis to sulfur deprivation[15]. Encoded by short open reading frames (sORF), small proteins take part in the developmental processes of plant and animal[21,22]. However, there has been no protocol to search any amino acid-rich proteins and small proteins in a complete proteome by now.

The HICL table integrates the the every protein name, ID number with the name abbreviation and-HUMAN and its MTS with its intrinsic values together, so it enables an ordinary biologist easely to make largescale analysis of the data, to perceive the details of the distribution patterns in the data, and to find all very acidic, basic, small, large and hydrophobic, highly cysteine-rich, highly aspartic acid-rich, highly glutamic acid-rich, highly lysine-rich, highly arginine-rich, highly serine-rich, highly threonine-rich, highly tryptophan-rich proteins and some other particular proteins in the human complete proteome. In addition, Ig heavy chain V-I region ND (Fragments)(|P01744|), Mucin-16(|Q8WXI7| ), Mucin-19(|Q7Z5P9|) and Mucin- 
$3 \mathrm{~A}(|\mathrm{Q} 02505|)$ have the zero values of molecular weight and $\mathrm{pI}$ in the HICL table, because their sequences contain ambiguous amino acid character $(\mathrm{X})$.

Any proteins with the values in the selected ranges of the physicochemical features can be screened out from the human complete proteome in the multi-sorted HICL table, for example, small- very acidic proteins, small-basic proteins, small-very acidic-hydrophobic proteins and small-basic-hydrophobic proteins. All these specific proteins will give us an explicit information to design a better preparation and separation protocol in human proteomics research. In adition, all Met-truncated sequences of the proteins with the values in the selected ranges of the physicochemical features can be copy from the multi-sorted HICL table for further analysis.

\section{Sorting all proteins of the human complete proteome by the names}

The rearrangement of the data in the HICL table can be accomplished by alpha- betically sorting of the Annot1 column. Some proteins which names are beginning with the same letter are grouped together; and within that grouping all proteins which names are beginning with the same two-letter sequence are grouped together; and so on. The rearranged data can show all proteins of the human complete proteome in alphabetical order based on their names. Some protein family members or protein variants can be generally grouped together in clusters, because the initial alphabets of their names are identical. This sorted table enable an ordinary biologist quickly to visualize and find the details of the distribution of physicochemical features in some protein family members and protein variants. For example, the majority of total 419 members of olfactory receptor family possess the high hydrophobicity values ranged from 0.5085 to 1.089 , except for Olfactory receptor 4N2 (Fragment) ($0.2999)$, Olfactory receptor $2 \mathrm{~T} 12$ (0.4367), Olfactory receptor 1L1(0.4496), Olfactory receptor $8 \mathrm{~S} 1(0.462)$, Olfactory receptor 2T33(0.4683).

There are the groups of the proteins which names are beginning with ankyrin, cyclin, cysteine-rich, DDB1, DNA, F-box, histone, nucleolar, olfactory, PDZ, transmembrane, zinc finger, etc. For example, figure 1 shows the cluster of protein family members and protein variants of alpha-2,8- sialyltransferase 8 in the HICL table sorted by the names.

The total number of the 20,687 protein-coding genes were predicted from the human genome[23], therefore, the set of 67911 entries in complete human proteome must contain many protein variants. So far, there has been no protocol to cluster all [Insert Running title of $<72$ characters] 
protein variants together in a complete proteome. By means of sorting all proteins of the human complete proteome by the names, all annotated protein variants can be comprehensively organized in clusters. so it enables an ordinary biologist easely to observe and perceive the all clusters of the protein variants in the sorted HICL table.

\section{Sorting all proteins of the human complete proteome by the Met-truncated}

\section{sequences}

The HICL table can be converted by alphabetically sorting of the MTS column. Some Met-truncated sequences are beginning with the same letter are grouped together; and within that grouping all Met-truncated sequences are beginning with the same two-letter sequence are grouped together; and so on. The rearranged data can show all proteins of the human complete proteome in alphabetical order based on their Met-truncated sequences and enable an ordinary biologist to make largescale analysis of the $\mathrm{N}$-terminal amino acid sequences in the human complete proteome. Interestingly, some protein family members or protein variants can be usually grouped together in clusters, because their N-terminal amino acid sequences are identical. Some protein family members and protein variants have different $\mathrm{N}$-terminal amino acid sequences, so they may take mixed pattern of dispersed and aggregated distributions in the HICL table sorted by the Met-truncated sequences.

Most neighbouring different proteins have the same two or three amino acid residues in their $\mathrm{N}$-terminal amino acid sequences. Thus, like in some prokaryote proteome projects[24,25], N-terminal amino acid sequences of the human complete proteome have sufficient specificity for protein identification in human proteome projects.

\section{Searching of all protens in the human complete proteome by query sequences or the names}

The data of the HICL table can be quickly searched by the text of query sequences, the names or part of name. The peptides from Mass Spectrometry (MS)based peptide sequencing can be as query sequences to search the precursor sequences in the HICL table. Using the words of ankyrin, cyclin, cysteine-rich, DDB1, DNA, Fbox, histone, nucleolar, olfactory, PDZ, receptor, transmembrane, zinc finger, etc, some protein groups can be quickly identified and located by searching the alphabetically sorted data in the HICL table.

[Insert Running title of $<72$ characters] 
In comparison with the HICL table sorted by protein names, the HICL table sorted by the Met-truncated sequences has no alphabetical order in protein names. The difference of N-terminal amino acid sequences of protein family members and protein variants can be estimated by their distribution in the HICL table sorted by the Met-truncated sequences. Therefore, the function of searching is critical to reveal the distribution of protein family members and protein variants in the HICL table sorted by the Met-truncated sequences. For example, figure 2 shows the result of the searching by the text of alpha-2,8- sialyltransferase 8 and demonstrates the distribution pattern of protein family members and protein variants of alpha-2,8sialyltransferase 8 in the HICL table sorted by the Met-truncated sequences.

\section{Illustrating the physicochemical maps of the human complete proteome}

The data matrix in the HICL table contains multidimensional quantitative coordinates to locate all proteins in the human complete proteome. The all proteins of the human complete proteome can create a map in the multidimentional space. This map can be described as the physichemical structure of the human complete proteome, but can not be directly demonstrated for us. This map can be projected into any coordinate or two-dimensional space to generate an image to visualize the distribution patterns of one or two physicochemical features in the human complete proteome. The $\mathrm{pI}$ distribution in human complete proteome show a bimodal distribution(figure3). The distributions of individual amino acid versus sequence length were demonstrated in the additional file named as "distributions versus sequence length". The maps in Figure4 were selected from the additional files to show the distributions of the amino aicds (Cys ,Leu, Lys,Pro) versus sequence length. The distributions of the amino aicds (Asp,Glu,Arg, Lys,His, Cys,Tyr) with an ionizable side-chain versus $\mathrm{pI}$ were all demonstrated in figure 5.

According to this bimodal distribution(figure3), normal acid-base state from 7.35 to 7.45 of $\mathrm{pH}$ values in human blood is beneficial for the stability of all human proteins to avoid the aggregation of protein at $\mathrm{pI}$ as best as possible. In the maps of the distributions of individual amino acid versus sequence length, the green loess curves extends tightly around the corresponding red average line in the range of about sequence length $\leq 1000$ and then gradually deviates from the corresponding red average line in the range of about sequence length $>1000$. It means that any sub- 
group proteins in the range of about sequence length $\leq 1000$, for example, small proteins, has almost as same as the average values of amino acid composition in human complete proteome. With weak acid-base groups and low-abundance in the human complete proteome, the amino aicds(His, Cys, Tyr) have L-shaped trends of distributions versus $\mathrm{pI}$, but the trends of the amino aicds(Cys,Tyr) with weak acid groups decline in the range of high $\mathrm{pI}$ and the trend of the amino aicd(His) with weak base group declines in the range of low pI. With strong acid-base groups and highabundance in the human complete proteome, the amino aicds(Asp,Glu,Arg) have Sshaped trends of distributions versus pI, but the trend of the amino aicd(Lys) declines in the range of low $\mathrm{pI}$ and high $\mathrm{pI}$ and have $\mathrm{C}$-shaped trends of distributions versus $\mathrm{pI}$. In a word, the amino aicds(Asp,Glu) have symmetrical trend of the distributions versus pI, but the amino aicds(Arg, Lys) have local asymmetrical trend of the distributions versus $\mathrm{pI}$ in human complete proteome.

\section{Creating a particular fusion proteome via the HICL table}

By numerically sorting the $\mathrm{pI}$ column in either ascending or descending order, all Met-truncated sequences in MTS column were respectively copied and pasted into A and B columns in sheet1, and then sheet1 was saved as a txt document named as fusion-proteome1. The values of isoelectric point(pI) of all fusion proteins in fusionproteome1 had been computed using Compute pI/Mw tool (http://web.expasy.org/ compute_pi/). The $\mathrm{pI}$ distribution in fusion-proteome1 has been illustrated in figure6.

By comparison between figure 3 and figure6, it could be asserted that protein sequence, besides amino acid properties, can influence the modal distribution of protein isoelectric points and result in the maldistribution of protein isoelectric points in particular fusion proteome. This result supplements Georg F. Weiller's idea: “ The modal distribution of protein isoelectric points reflects amino acid properties rather than sequence evolution" [26].

\section{Conclusions}

This HICL table can be orderly reorganized by numerically or alphabetically sorting any colume. Any proteins with the values in the selected ranges of the physicochemical features can be screened out from the human complete proteome in [Insert Running title of $<72$ characters] 
the multi-sorted HICL table, and all very acidic, basic, small, large , hydrophobic, highly aspartic acid-rich, highly glutamic acid-rich, highly lysine-rich, highly arginine-rich and some other particular proteins can be easily found in the human complete proteome. Some protein family members or protein variants can be generally grouped together in clusters, because the initial alphabets of their names or their N-terminal amino acid sequences are identical. The data of the HICL table can be quickly searched by the text of query sequence, the name or part of name, so any protein family can be quickly identified and located by searching the alphabetically sorted data in the HICL table. Based on the data in the HICL table, the distribution patterns of any one or two physicochemical features in the human complete proteome could be visualized. A particular fusion proteome can be created via the HICL table for theoretical research of some feature in proteome.

The HICL table contains almost complete information of the set of human complete proteome entries downloaded from the Universal Protein Resource (UniProt) and the values of AAC, AAC-derived features of all proteins. Based on the integration of the data matrix and the functions of sorting and searching, an overview on the distribution of the physicochemical features of all proteins in the human complete proteome and the details of the distribution patterns of the physicochemical features in some protein family members and protein variants can be quickly illustrated in the HICL table. Therefore, the HICL table can be a robust tool for exploiting the human complete proteome and for exploring the feature of proteome. This method can be applied to the complete proteomes of other species.

Based on the data in the HICL table, the unbalanced distribution of the amino aicds(Arg, Lys) in high pI proteins of human complete proteome and the maldistribution of protein isoelectric points in particular fusion proteome have been discovered.

\section{Materials and Methods}

\section{The establishment of HICL excel table}

The set of human complete proteome entries in FASTA format had been downloaded from the Universal Protein Resource (UniProt) [1] and demonstrated in the additional file named as "human complete proteome". The original sequences of proteins in FASTA format had been transformed into the amino acid sequences of the [Insert Running title of $<72$ characters] 
proteins in plain-text format that were then converted into the Met-truncated sequences(MTSs) by eliminating the initial methionine. The abundances of amino acids in the MTSs can be calculated as the values of AAC. The MTSs and annotations of the human complete proteomes had been extracted from the set of human complete proteome entries by the $\mathrm{R}$ statistical programming language. The values of AAC, sequence length, molecular weight, isoelectric point(pI) and hydrophobicity of all MTSs in human complete proteome had been computed using the R statistical programming language, ProPAS software[19] and Compute pI/Mw tool (http://web.expasy.org/ compute_pi/). The all values of the results with corresponding MTSs and annotations were imported into Microsoft Excel(2007) to generate a excel table for further operating analysis. This excel table has been designated as HICL.

\section{The manipulation of the HICL excel table}

In Excel, the tool on the Remove Duplicates section of the Data tab can provide the function for removing all duplicate rows from the range of data and leaving only the first instance of each row. Excel displays a message confirming how many duplicates were removed and the number of unique values remaining, so the number of redundant rows of numeric values of physicochemical features in the data of the HICL table can be determined.

Using the tool on the Sort \& Filter section of the Data tab, the data of a excel table can be reorganized by numerically or alphabetically sorting a specific column in either ascending or descending order (from the smallest to largest numeric value or from largest to the smallest numeric value ) and ( $\mathrm{A}$ to $\mathrm{Z}$ or $\mathrm{Z}$ to $\mathrm{A}$ ). The data of the HICL table can be quickly reorganized by respectively sorting any column.

The HICL table has its multidimensional quantitative coordinates, so the data in the HICL table can be grouped according to not only a coordinate but also their coordinates. After sorting by first physicochemical feature, the rows in which the values of first physicochemical feature are below or/and above criteria can be deleted. The deleted data of the HICL table continues to be sorted by second physicochemical feature, New reorganized data can show the details of the second physicochemical feature distribution of the proteins with the values in the selected range of first physicochemical feature. To continues these steps with other physicochemical feature, 
and so on, any proteins with the values in the selected ranges of the physicochemical features can be screened out from the human complete proteome.

Using the tool on the Find \& Select section of the Home ribbon, the data of the HICL table can be searched by opening the Find and Replace dialog, pasting or typing the text of query sequence, the protein name or part of name that you are searching for in the "Find" box, and then Clicking "Find All" to generate a list of all rows that contain that text.

\section{The illustration of the distribution of physicochemical features in the human complete proteome}

Based on the data in the HICL table, the map of the distribution of physicochemical features in human complete proteome had been illustrated by the $\mathrm{R}$ statistical programming language. In the maps, the green loess curve and the red average line can clearly show the trend of an individual amino acid distribution.

\section{Ethics}

Ethical approval was not applicable for this type of study.

\section{Consent to publish}

Any consent to publish was not applicable for this study.

\section{Competing interest statement}

The author declares no competing financial interests.

\section{Authors' contributions}

Zhenhua Xie did all works in this study and wrote the manuscript. 


\section{Acknowledgements}

The author would like to acknowledge the supports from Shenzhen Bureau of Science,Technology and Information (Grant No. JCYJ20140417115840267 and JCYJ20150518162154828).

\section{Additional files}

Supplementary HICL excel table and the additional files "distributions versus sequence length' and "human complete proteome" can be found online at

\section{Abbreviations}

2D-PAGE: two-dimensional polyacrylamide gel electrophoresis; AAC: Amino acid composition; AAs: amino acids; Ala: Alanine; Annot1: Annotation1; Annot2: Annotation2; Arg: Arginine; Asp: Aspartic acid; Asn: Asparagine; Cys: Cysteine; DDB1: damage-specific DNA binding protein1; DNA: deoxyribonucleic acid; F-box: a protein structural motif of about 50 amino acids that mediates protein-protein interactions; Gln: Glutamine; Glu: Glutamic acid; Gly: Glycine; His: Histidine; HP: Hydrophobicity; ID: identification; Ile: Isoleucine; Leu: Leucine; Lys: Lysine; Met: Methionine; MS: Mass spectrometry; MTS: Met-truncated sequence(derived from full protein sequence by eliminating the initial methionine); MW: Molecular weight; NCBI: National Center for Biotechnology Information; NO: Number; PDZ: a common structural domain of 80-90 amino-acids found in the signaling proteins of bacteria, yeast, plants, viruses[1] and animals; Phe: Phenylalanine; pI: Isoelectric point; Pfam: a large collection of protein families, each represented by multiple sequence alignments and hidden Markov models (HMMs); Pro: Proline; Ser: Serine;

SL: Sequence length; sORF: short open reading frames;Thr: Threonine; Trp: Tryptophan; Tyr: Tyrosine; UniProt : Universal Protein Resource; Val: Valine.

\section{References}

1. Reorganizing the protein space at the Universal Protein Resource (UniProt). Nucleic acids research 2012, 40(Database issue):D71-75.

[Insert Running title of $<72$ characters] 
2. Database resources of the National Center for Biotechnology Information. Nucleic acids research 2015, 43(Database issue):D6-17.

3. Mulder NJ, Kersey P, Pruess M, Apweiler R: In silico characterization of proteins: UniProt, InterPro and Integr8. Molecular biotechnology 2008, 38(2):165-177.

4. Caffrey BE, Williams TA, Jiang X, Toft C, Hokamp K, Fares MA: Proteome-wide analysis of functional divergence in bacteria: exploring a host of ecological adaptations. PloS one 2012, 7(4):e35659.

5. Revuelta MV, van Kan JA, Kay J, Ten Have A: Extensive expansion of A1 family aspartic proteinases in fungi revealed by evolutionary analyses of 107 complete eukaryotic proteomes. Genome biology and evolution 2014, 6(6):1480-1494. 6. Alhaider AA, Bayoumy N, Argo E, Gader AG, Stead DA: Survey of the camel urinary proteome by shotgun proteomics using a multiple database search strategy. Proteomics 2012, 12(22):3403-3406.

7. Martins-de-Souza D, Guest PC, Guest FL, Bauder C, Rahmoune H, Pietsch S, Roeber S, Kretzschmar H, Mann D, Baborie A et al: Characterization of the human primary visual cortex and cerebellum proteomes using shotgun mass spectrometrydata-independent analyses. Proteomics 2012, 12(3):500-504.

8. Rabilloud T, Chevallet M, Luche S, Lelong C: Two-dimensional gel electrophoresis in proteomics: Past, present and future. Journal of proteomics 2010 , 73(11):2064-2077.

9. Benso A, Di Carlo S, Ur Rehman H, Politano G, Savino A, Suravajhala P: A combined approach for genome wide protein function annotation/prediction. Proteome science 2013, 11(Suppl 1):S1.

10. He Z, Zhang C, Xu Y, Zeng S, Zhang J, Xu D: MUFOLD-DB: a processed protein structure database for protein structure prediction and analysis. BMC genomics 2014, 15 Suppl 11:S2.

11. Kumar M, Thakur V, Raghava GP: COPid: composition based protein identification. In silico biology 2008, 8(2):121-128.

12. Chaurasiya M, Chandulah GB, Misra K, Chaurasiya VK: Nearest-neighbor classifier as a tool for classification of protein families. Bioinformation 2010, 4(9):396-398.

13. Mistry J, Coggill P, Eberhardt RY, Deiana A, Giansanti A, Finn RD, Bateman A, Punta M: The challenge of increasing Pfam coverage of the human proteome. Database : the journal of biological databases and curation 2013, 2013:bat023. 14. Roy S, Martinez D, Platero H, Lane T, Werner-Washburne M: Exploiting amino acid composition for predicting protein-protein interactions. PloS one 2009, 4(11):e7813.

15. Good DM, Mamdoh A, Budamgunta H, Zubarev RA: In silico proteome-wide amino aCid and elemental composition (PACE) analysis of expression proteomics data provides a fingerprint of dominant metabolic processes. Genomics, proteomics \& bioinformatics 2013, 11(4):219-229.

16. Huang $\mathrm{CH}$, Chou SY, Ng KL: Improving protein complex classification accuracy using amino acid composition profile. Computers in biology and medicine 2013, 43(9):1196-1204.

17. Hayat M, Khan A: WRF-TMH: predicting transmembrane helix by fusing composition index and physicochemical properties of amino acids. Amino acids 2013, 44(5):1317-1328.

18. Wolstencroft K, Owen S, Horridge M, Krebs O, Mueller W, Snoep JL, du Preez F, Goble C: RightField: embedding ontology annotation in spreadsheets.

Bioinformatics 2011, 27(14):2021-2022.

[Insert Running title of $<72$ characters] 
19. Wu S, Zhu Y: ProPAS: standalone software to analyze protein properties. Bioinformation 2012, 8(3):167-169.

20. Wong HW, Liu Q, Sun SS: Biofortification of rice with lysine using endogenous histones. Plant molecular biology 2015, 87(3):235-248.

21. Slavoff SA, Mitchell AJ, Schwaid AG, Cabili MN, Ma J, Levin JZ, Karger AD, Budnik BA, Rinn JL, Saghatelian A: Peptidomic discovery of short open reading frame-encoded peptides in human cells. Nature chemical biology 2013, 9(1):59-64. 22. Su M, Ling Y, Yu J, Wu J, Xiao J: Small proteins: untapped area of potential biological importance. Frontiers in genetics 2013, 4:286.

23. Kim MS, Pinto SM, Getnet D, Nirujogi RS, Manda SS, Chaerkady R, Madugundu AK, Kelkar DS, Isserlin R, Jain S et al: A draft map of the human proteome. Nature 2014, 509(7502):575-581.

24. Wilkins MR, Gasteiger E, Tonella L, Ou K, Tyler M, Sanchez JC, Gooley AA, Walsh BJ, Bairoch A, Appel RD et al: Protein identification with N and C-terminal sequence tags in proteome projects. Journal of molecular biology 1998, 278(3):599608.

25. Yoshizawa AC, Fukuyama Y, Kajihara S, Kuyama H, Tanaka K: Computational survey of sequence specificity for protein terminal tags covering nine organisms and its application to protein identification. Journal of proteome research 2015, 14(2):756767.

26. Weiller GF, Caraux G, Sylvester N: The modal distribution of protein isoelectric points reflects amino acid properties rather than sequence evolution. Proteomics 2004, 4(4):943-949.

\section{Tables}

Table1: The values and ranges of the grouping criteria for every feature

\begin{tabular}{|c|c|c|c|c|c|}
\hline $\begin{array}{c}\text { colum } \\
\mathrm{n}\end{array}$ & groupl & groupll & groupllI & groupIV & groupV \\
\hline AAC & $\begin{array}{c}0.0- \\
<0.05\end{array}$ & $0.05-<0.1$ & $0.1-<0.15$ & $0.15 \%-<0.20$ & $\geq 0.20$ \\
\hline $\mathrm{SL}$ & $0-<200$ & $200-<500$ & $500-<1000$ & $1000-<2000$ & $\geq 2000$ \\
\hline $\mathrm{MW}$ & $0-<23 \mathrm{kd}$ & $\begin{array}{l}23 \mathrm{kd}- \\
<57.5 \mathrm{kd}\end{array}$ & $\begin{array}{c}57.5 \mathrm{kd}- \\
<115 \mathrm{kd}\end{array}$ & $\begin{array}{c}115 \mathrm{kd}- \\
<230 \mathrm{kd}\end{array}$ & $\geq 230 \mathrm{kd}$ \\
\hline $\mathrm{pI}$ & $0-<4.0$ & $4.0-<6.0$ & $6.0-<8.0$ & $8.0-<10.0$ & $\geq 10.0$ \\
\hline $\mathrm{HP}$ & $-<-1.0$ & $-1.0-<-0.5$ & $-0.5-<0.0$ & $0.0-<0.5$ & $\geq 0.5$ \\
\hline
\end{tabular}

The table 2: The distributions of all proteins in the human complete proteome.

\begin{tabular}{|c|c|c|c|c|c|}
\hline feature & groupl & groupll & groupIII & groupIV & groupV \\
\hline Ala & 15993 & 40795 & 9427 & 1344 & 352 \\
\hline Cys & 61961 & 5218 & 543 & 74 & 115 \\
\hline Asp & 40171 & 26228 & 1292 & 170 & 50 \\
\hline Glu & 19625 & 38162 & 8435 & 1345 & 344 \\
\hline Phe & 52084 & 15021 & 726 & 60 & 20 \\
\hline
\end{tabular}

[Insert Running title of $<72$ characters] 


\begin{tabular}{|c|c|c|c|c|c|}
\hline Gly & 19763 & 39264 & 7437 & 1004 & 443 \\
\hline His & 62991 & 4740 & 158 & 17 & 5 \\
\hline Ile & 44232 & 22479 & 1115 & 72 & 13 \\
\hline Lys & 30640 & 31115 & 5209 & 730 & 217 \\
\hline Leu & 4359 & 29812 & 27788 & 5054 & 898 \\
\hline Met & 66230 & 1601 & 69 & 9 & 2 \\
\hline Asn & 55168 & 12312 & 385 & 39 & 7 \\
\hline Pro & 27881 & 31382 & 6819 & 1364 & 465 \\
\hline Gln & 41510 & 24404 & 1716 & 205 & 76 \\
\hline Arg & 26816 & 35489 & 4681 & 722 & 203 \\
\hline Ser & 9285 & 42439 & 13399 & 2172 & 616 \\
\hline Thr & 32736 & 33031 & 1809 & 237 & 98 \\
\hline Val & 22815 & 41142 & 3660 & 245 & 49 \\
\hline Trp & 66602 & 1250 & 51 & 5 & 3 \\
\hline Tyr & 62174 & 5513 & 175 & 28 & 21 \\
\hline SL & 35926 & 19119 & 9045 & 3106 & 715 \\
\hline MW & 36762 & 18872 & 8734 & 2887 & 656 \\
\hline pI & 584 & 22680 & 15630 & 23892 & 5125 \\
\hline HP & 4678 & 21003 & 31205 & 8388 & 2637 \\
\hline
\end{tabular}

\section{Figures}

Figure1: The cluster of alpha-2,8- sialyltransferase 8 family members and variants in the HICL table sorted by the names

\begin{tabular}{c|r|r|r|r|r|}
\multicolumn{1}{c|}{ No } & \multicolumn{1}{c}{ SL } & \multicolumn{1}{c}{ MW } & \multicolumn{1}{c|}{ pI } & \multicolumn{1}{c|}{ HP } & \multicolumn{1}{c|}{ Annotl } \\
\hline 2976 & 504 & 53764.05 & 6.38 & -0.2445 Alpha-1-syntrophin \\
\hline 2977 & 374 & 42298.71 & 9.48 & -0.2159 Alpha-2, 8-sialyltransferase 8B \\
\hline 2978 & 353 & 40118.33 & 9.22 & -0.1645 Alpha-2, 8-sialyltransferase 8B \\
\hline 2979 & 331 & 37533.38 & 9.31 & -0.1609 Alpha-2, 8-sialyltransferase 8B (Fragment) \\
\hline 2980 & 375 & 43763.67 & 9.19 & -0.1572 Alpha-2, 8-sialyltransferase 8E \\
\hline 2981 & 344 & 39938.3 & 9.42 & -0.1484 Alpha-2, 8-sialyltransferase 8E \\
\hline 2982 & 53 & 5780.68 & 6.17 & 0.0019 Alpha-2, 8-sialyltransferase 8E \\
\hline 2983 & 39 & 4167.93 & 6.13 & 0.3513 Alpha-2, 8-sialyltransferase 8E \\
\hline 2984 & 397 & 44704.69 & 9.19 & -0.2014 Alpha-2, 8-sialyltransferase 8F \\
\hline 2985 & 128 & 14187.55 & 9.3 & -0.2233 Alpha-2, 8-sialyltransferase 8F (Fragment) \\
\hline 2986 & 449 & 48825.62 & 9.8 & 0.0261 Alpha-2A adrenergic receptor \\
\hline
\end{tabular}

Figure2: The distribution of alpha-2,8- sialyltransferase 8 family members and variants in the HICL table sorted by the M-truncated sequences

[Insert Running title of $<72$ characters] 
bioRxiv preprint doi: https://doi.org/10.1101/093971; this version posted December 14, 2016. The copyright holder for this preprint (which was not certified by peer review) is the author/funder. All rights reserved. No reuse allowed without permission.

Zhenhua Page 17

\begin{tabular}{|c|c|c|c|}
\hline HICL table. $x l s x$ & HICL table & $\$ A C \$ 43524$ & Alpha-2,8-sialyl transferase $8 \mathrm{~B}$ \\
\hline HICL table. $x l s x$ & HICL table & $\$ A C \$ 43525$ & Alpha-2, 8-sialyl transferase $8 \mathrm{~B}$ \\
\hline HICL table. xlsx & HICL table & $\$ A C \$ 43526$ & Alpha-2, 8-sialyl transferase 8B (Fragment) \\
\hline HICL table. $x l s x$ & HICL table & $\$ A C \$ 46003$ & Alpha-2, 8 -sialyl transferase $8 \mathrm{~F}$ \\
\hline HICL table. xlsx & HICL table & $\$ A C \$ 47154$ & Alpha-2, 8-sialyltransferase $8 \mathrm{E}$ \\
\hline HICL table. xlsx & HICL table & $\$ A C \$ 47155$ & Alpha-2, 8-sialyl transferase $8 \mathrm{E}$ \\
\hline HICL table. xlsx & HICL table & $\$ A C \$ 59316$ & Alpha-2, 8-sialyltransferase $8 \mathrm{E}$ \\
\hline HICL table. xlsx & HICL table & $\$ A C \$ 59317$ & Alpha-2, 8-sialyltransferase $8 \mathrm{E}$ \\
\hline HICL table. xlsx & HICL table & $\$ A C \$ 67184$ & Alpha-2, 8-sialyl transferase $8 \mathrm{~F}$ (Fragment) \\
\hline
\end{tabular}

Figure3: The pI distribution in human complete proteome

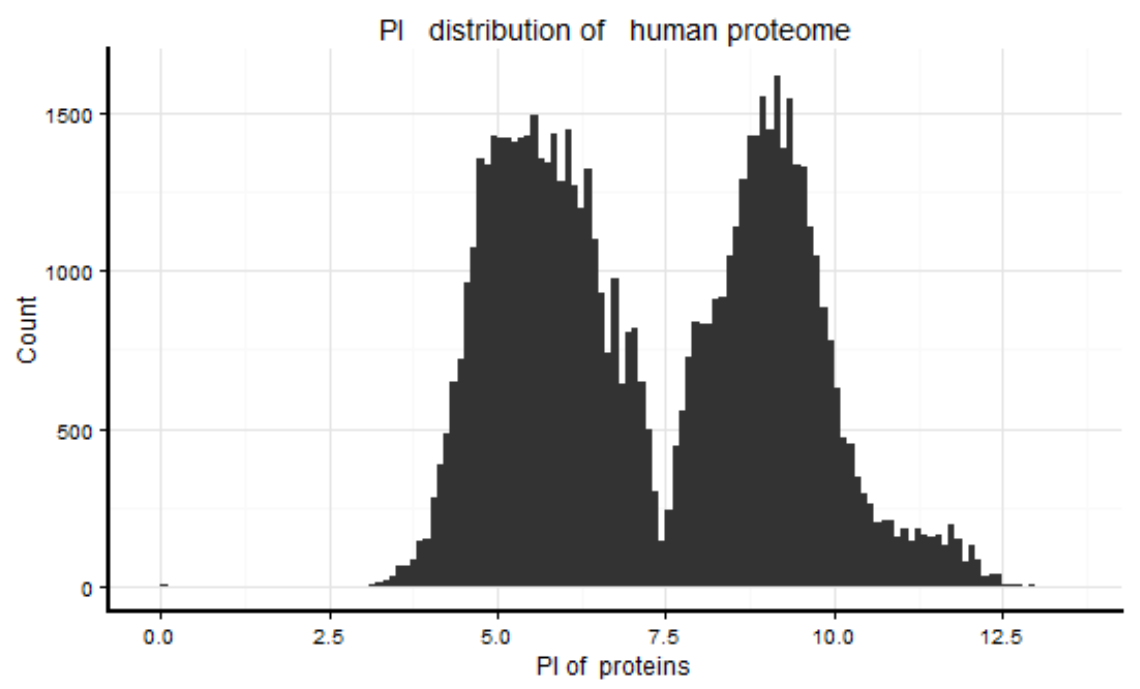

Figure4: The distributions of the amino aicds (Cys ,Leu, Lys,Pro) versus

sequence length
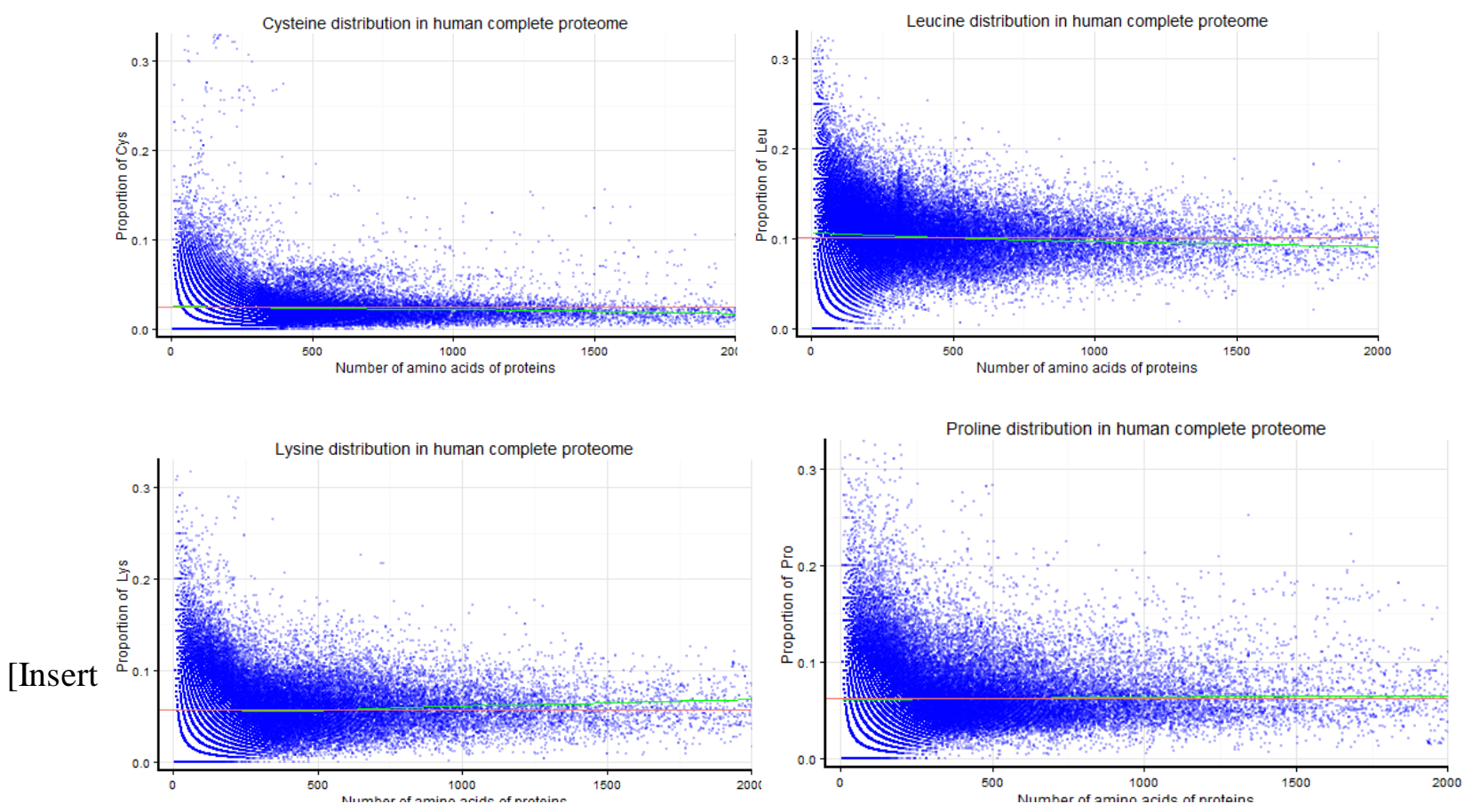
Figure5: The distributions of the amino aicds (Asp,Glu,Arg, Lys,His, Cys,Tyr) versus pI
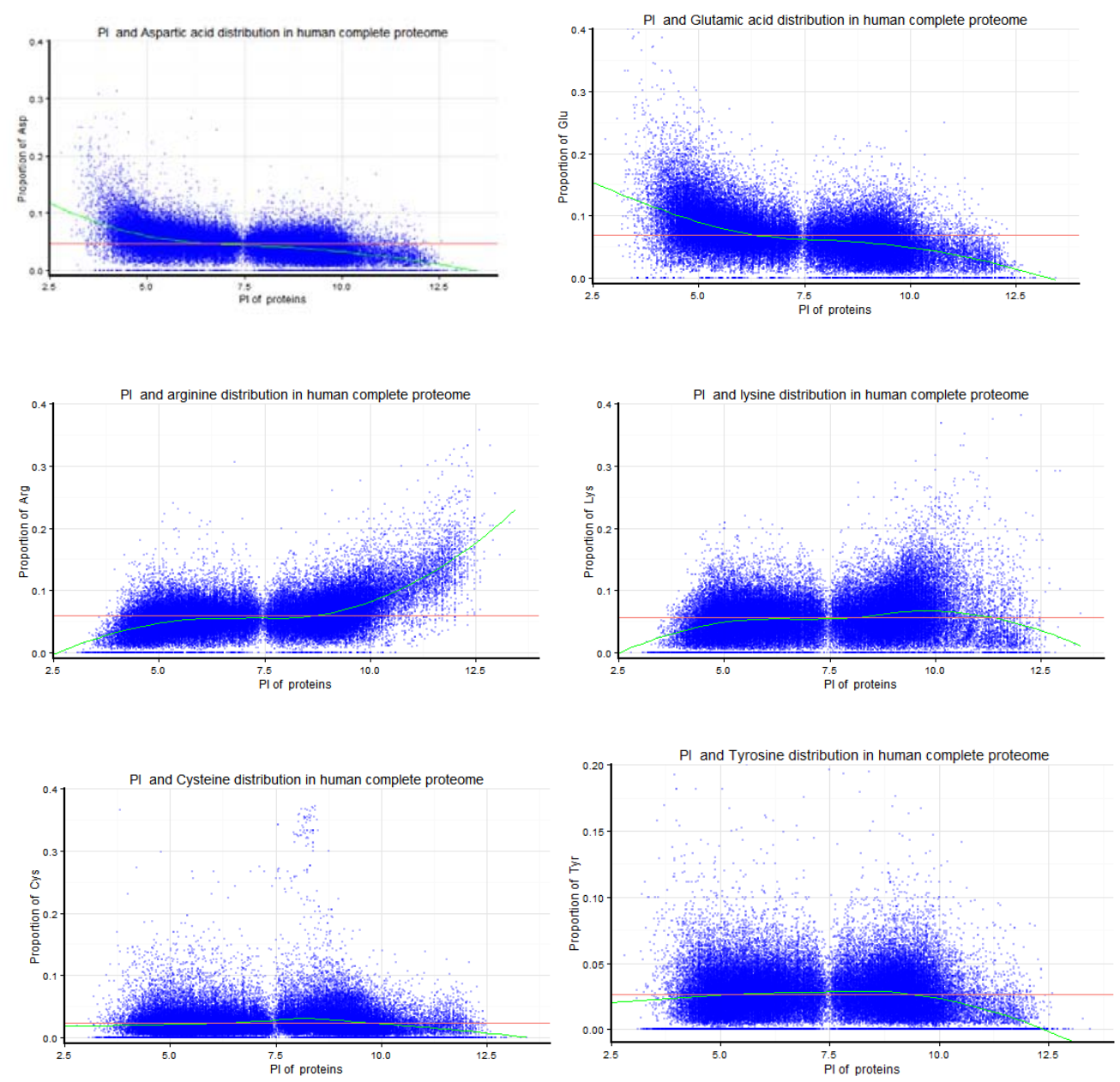

[Insert Ri

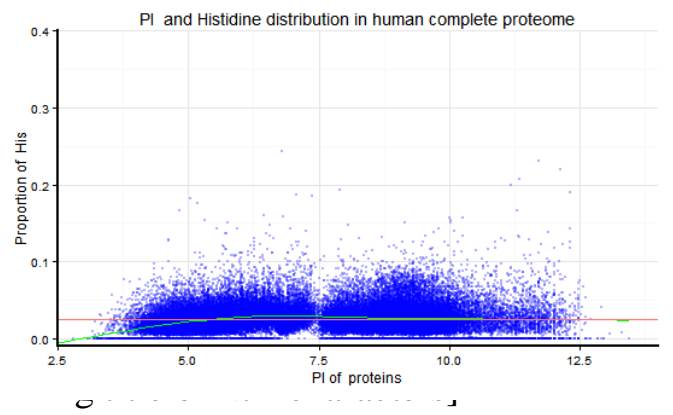


Figure6: The pI distribution in fusion-proteome1

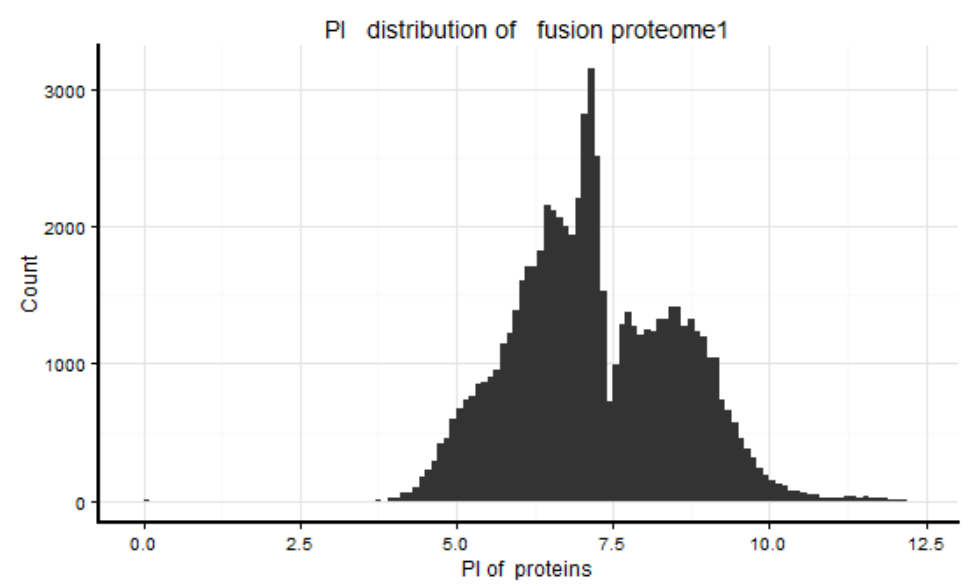

[Insert Running title of $<72$ characters] 
bioRxiv preprint doi: https://doi.org/10.1101/093971; this version posted December 14, 2016. The copyright holder for this preprint (which was not certified by peer review) is the author/funder All rights reserved No reyse allowed without permission.
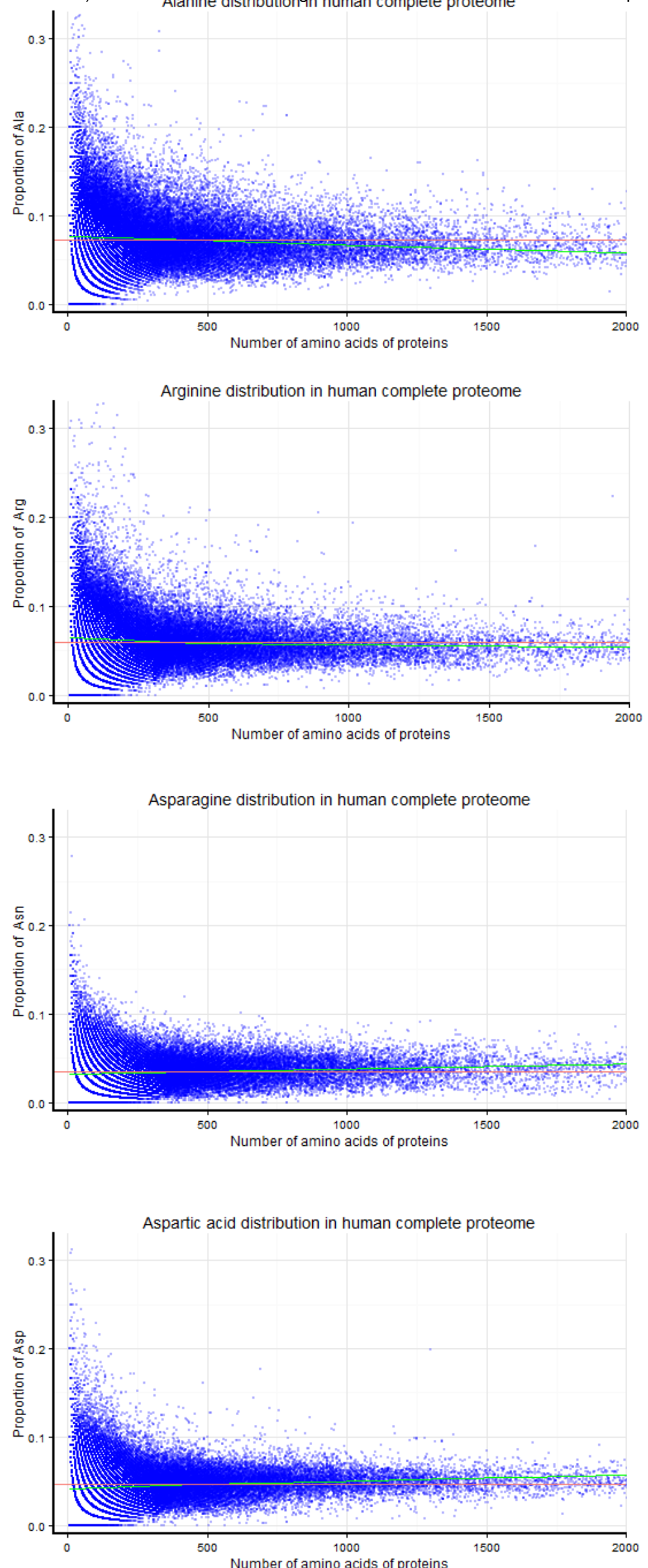
bioRxiv preprint doi: https://doi.org/10.1101/093971; this version posted December 14, 2016. The copyright holder for this preprint (which was not certified by peer review) is the author/funder All rights reserved. No reuse allowed without permission.
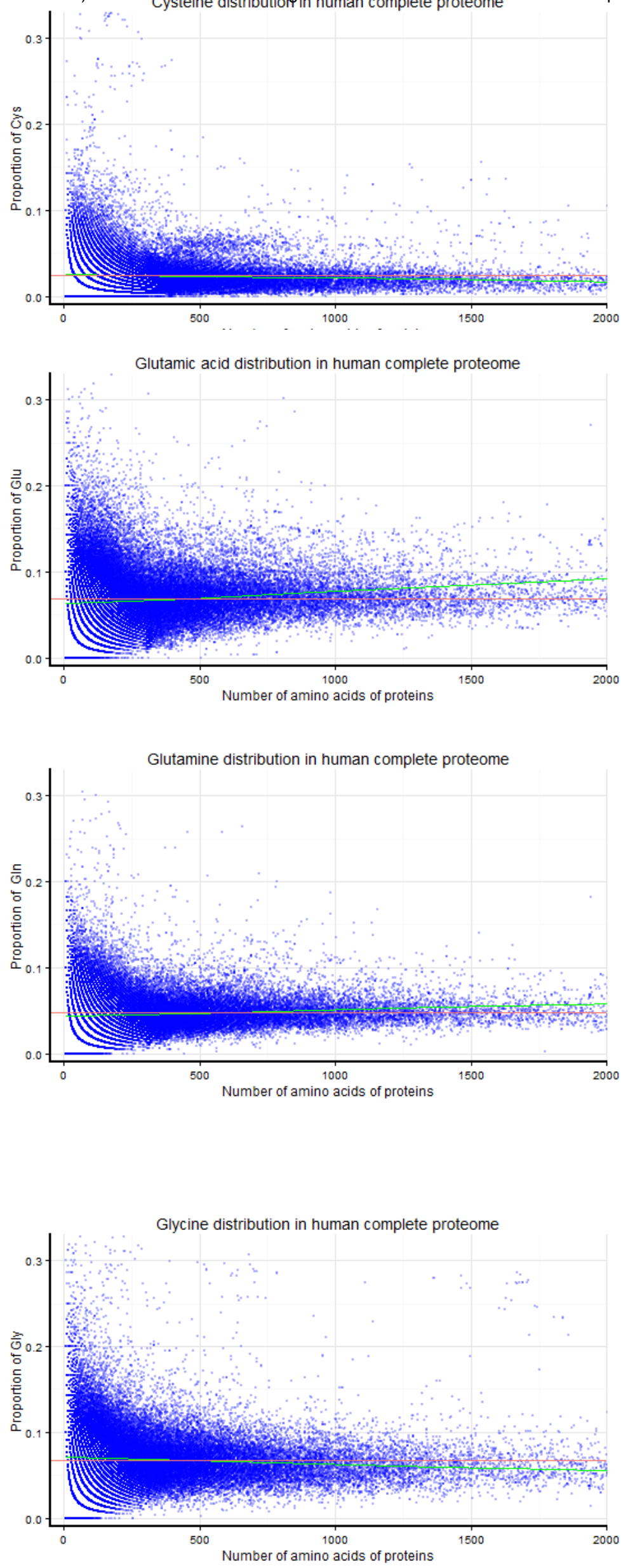
bioRxiv preprint doi: https://doi.org/10.1101/093971; this version posted December 14, 2016. The copyright holder for this preprint (which was not certified by peer review) is the author/funder All rights reseryed No reuse allowed without permission.
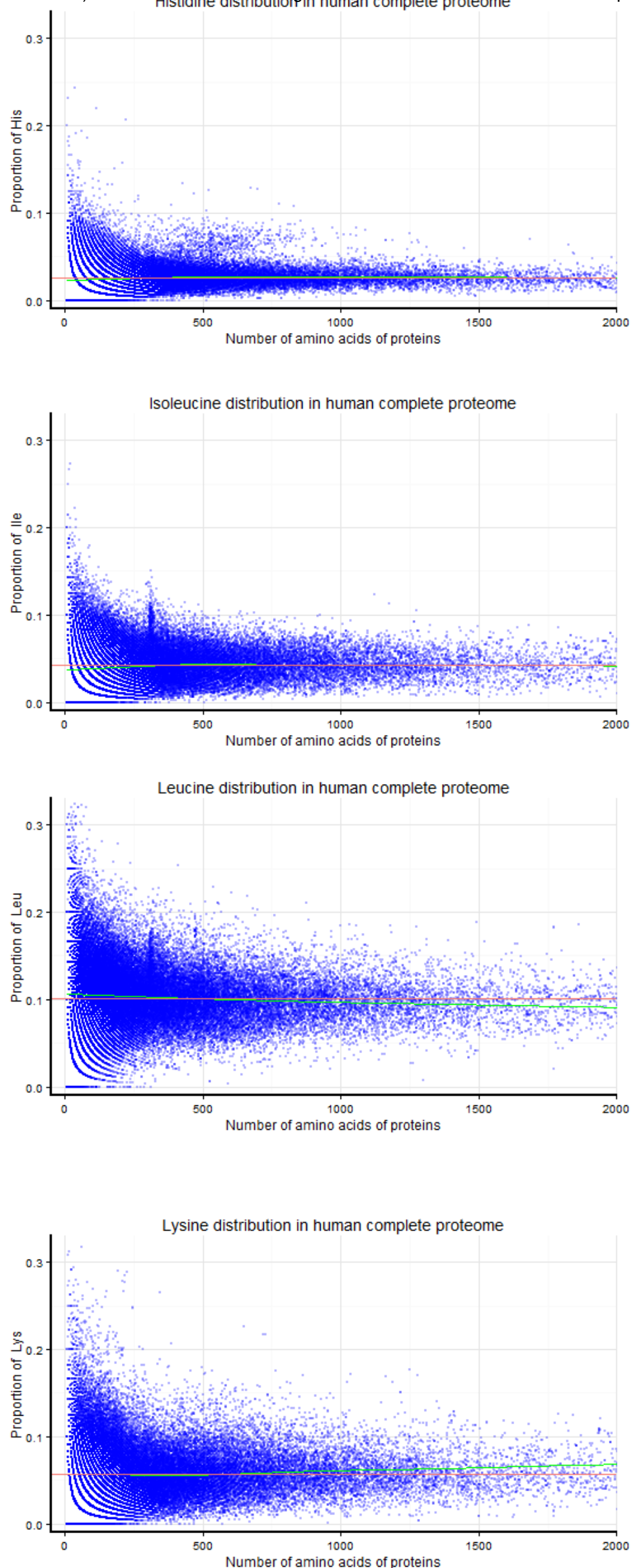
bioRxiv preprint doi: https://doi.org/10.1101/093971; this version posted December 14, 2016. The copyright holder for this preprint (which was not certified by peer review) is the author/funder All rights reserved No reuse allowed without permission.
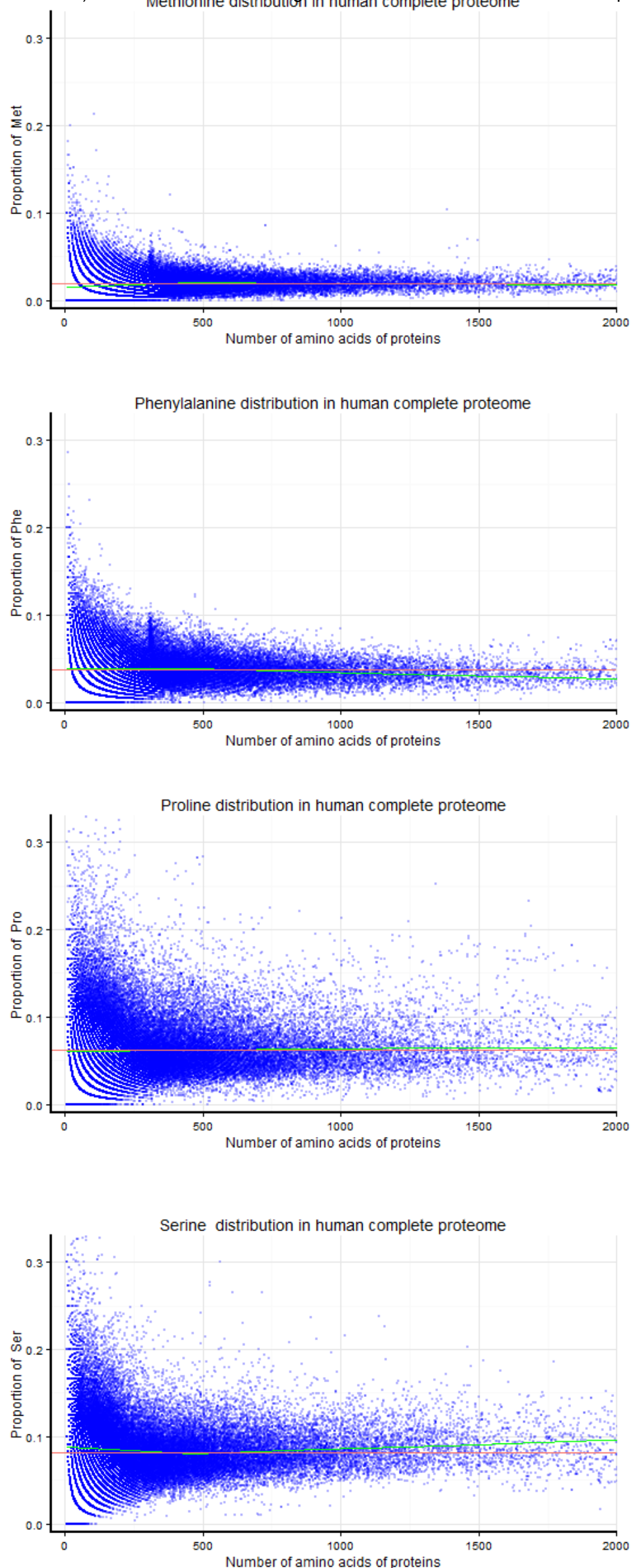
bioRxiv preprint doi: https://doi.org/10.1101/093971; this version posted December 14, 2016. The copyright holder for this preprint (which was not certified by peer review) is the author/funder. All rights reserved. No reuse allowed without permission.
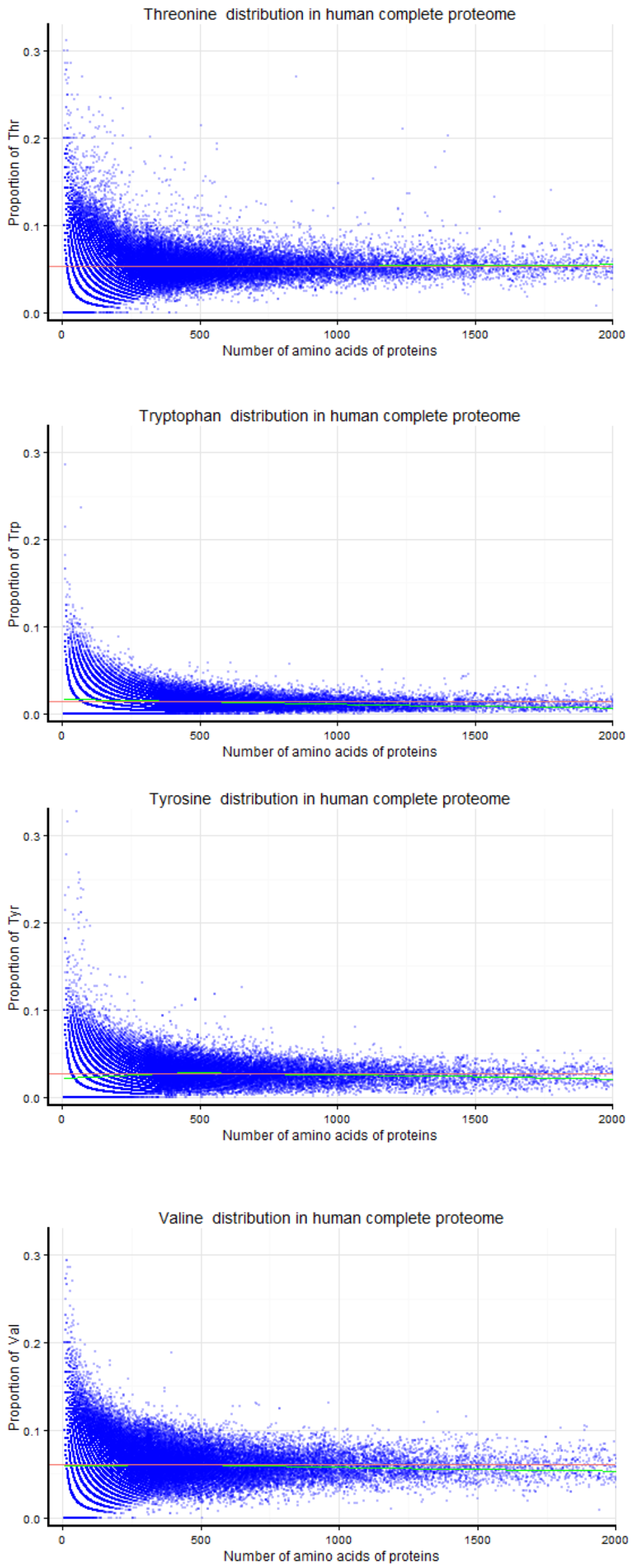